enrolled in HF rehabilitation programmes reflecting poor national provision. Two-thirds of patients lived outside of London, making it impractical for them to frequently visit our hospital. Hence a hospital-based rehabilitation programme would not improve this care priority. Added questions demonstrated less than optimal numbers receive exercise education within clinic.

Conclusion This audit demonstrated that a tertiary HF service has high rates of documentation, follow-up and compliance with established medical therapies. Notably many patients did not receive cardiac rehabilitation. This may be influenced by geographical limitations and the configuration of local services. To improve patient management further, alternative strategies including telehealth and enhanced multi-disciplinary team education are currently being explored.

\section{SPECIALIST INTERVENTION LEADS TO IMPROVED IN- PATIENT OUTCOMES IN PATIENTS WITH DECOMPENSATED HEART FAILURE: IMPACT OF INTRODUCING A HEART FAILURE TEAM}

\section{doi:10.1136/heartjnl-2012-301877b.14}

J Masters, ${ }^{*}$ I Anton, J Szymanski, E Greenwood, J Grogono, D Kelly, P J Cowburn. University Hospital Southampton, Hampshire, UK

In the Health Care Commission Audit in 2005, our hospital had an in-patient (IP) mortality of $30 \%$. A Heart Failure Team (HFT) was introduced to provide specialist in-patient care wherever the patients presented. The HFT was composed of two specialist nurses, a part time pharmacist and a clinical fellow and was led by a Consultant Cardiologist with a special interest in HF. The service commenced in April 2008. In the first year of the service 211 IPs were seen by the HFT. The mean age was 72.0 years (SD \pm 13.0 ), $40 \%$ were female, $53 \%$ had ischaemic heart disease and $28 \%$ were diabetic. Examination findings on admission revealed a mean heart rate of $89( \pm 26) \mathrm{bpm}$ and a mean systolic BP of 126 ( \pm 25$) \mathrm{mm} \mathrm{Hg}$; mean QRS duration was 116 ( \pm 44$) \mathrm{ms} .79 \%$ had an IP echo: of these $70 \%$ were classified as having moderate/severe left ventricular systolic dysfunction with $15 \%$ having preserved LV systolic function. Admission bloods revealed a mean $\mathrm{Na}$ of 135 $( \pm 6) \mathrm{mmol} / \mathrm{l}$, urea $12( \pm 12) \mathrm{mmol} / \mathrm{l}$, eGFR $51( \pm 22)$ and $\mathrm{Hb} 124$ $( \pm 23) \mathrm{g} / \mathrm{l}$. Mean length of stay (LOS) was 19 ( \pm 18$)$ days. In the preceding 6 months 215 patients were coded with a primary diagnosis for HF. Subsequent case note review confirmed that 196 patients had been correctly coded. The baseline characteristics and outcome of these 196 patients are described. The mean age was 73.5 years $( \pm 14.7), 36 \%$ were female, $51 \%$ had ischaemic heart disease and $26 \%$ were diabetic. Examination findings on admission revealed a mean heart rate of $87( \pm 21) \mathrm{bpm}$ and a mean systolic BP of $126( \pm 28) \mathrm{mm} \mathrm{Hg}$; mean ORS duration was 117 $( \pm 37) \mathrm{ms} .82 \%$ had an IP echo: of these $63 \%$ were classified as moderate/severe left ventricular systolic dysfunction with $17 \%$ having preserved LV systolic function. Admission bloods revealed a mean $\mathrm{Na}$ of $135( \pm 6) \mathrm{mmol} / \mathrm{l}$, urea $11( \pm 12) \mathrm{mmol} / \mathrm{l}$, eGFR 48 $( \pm 23)$ and $\mathrm{Hb} 122( \pm 22) \mathrm{g} / \mathrm{l}$. Mean LOS was $17( \pm 19)$ days. All ns vs HFT baseline demographics. Despite very similar baseline characteristics and LOS, outcomes were very different. The IP mortality in the pre-HFT cohort was $23 \%$ whereas the patients managed by the HFT had an IP mortality of $6 \%(p<0.001)$. Analysis of discharge medications shows patients managed by the HFT received higher doses of loop diuretics (mean bumetanide/ equivalent dose 2.4 ( \pm 1.5$) \mathrm{mg}$ HFT vs $1.6( \pm 1.2) \mathrm{mg}$ pre HFT, $\mathrm{p}<0.001)$ with more receiving intravenous diuretics during hospitalisation ( $88 \%$ of HFT patients vs $76 \%$ pre-HFT, $\mathrm{p}=0.002$ ). Discharge prescription of thiazide diuretics was also commoner in the HFT patients $(17 \%$ vs $5 \%, \mathrm{p}=0.001)$. ACE-inhibitors and/or ARBs $(91 \%$ vs $83 \%, p<0.05)$ and aldosterone receptor antagonists (68\% vs $44 \%, p<0.001)$ were prescribed more frequently by the HFT on discharge. $\beta$-blocker use was similar (HFT $63 \%$ vs preHFT $59 \%$, ns). The introduction of a specialist HFT dramatically reduced in-patient mortality. Improved use of evidence based therapies, together with more aggressive diuretic use, may contribute to the difference in patient outcomes.

\section{CAN WE PREDICT LIVER FIBROSIS PREOPERATIVE IN PATIENTS WHO UNDERGO HEART FAILURE SURGERY AND DOES IT INFLUENCE POSTOPERATIVE LIVER FUNCTION?}

doi:10.1136/heartjnl-2012-301877b.15

N Farre, ${ }^{*}$ L Tilling, A Rice, A Simon, N R Banner. Harefield Hospital, Harefield, Middlesex, UK

Background Liver dysfunction is common in patients with heart failure and may progress to irreversible fibrosis, which is predictive of poor prognosis. Our objective was to determine the frequency of liver fibrosis in patients who died after heart failure surgery (Insertion of ventricular assist device (VAD) or heart transplantation) and to identify predictors of liver fibrosis.

Methods We identified 19 patients who died after a median of 24 days after heart failure surgery. Liver sections were analysed postmortem for the presence of fibrosis which was staged according to the scheme: $0=$ none, $1=$ portal or limited perivenular/perisinusoidal, $2=$ portal, perivenular and sinusoidal, $3=$ bridging fibrosis and $4=$ cirrhosis. Clinically relevant fibrosis was defined as stage 3 or 4 . Pre- and post-operative data were analysed to identify predictors of fibrosis.

Results Mean age was $45 \pm 11$ years. $14 / 19$ patients were male. $84 \%$ had non-ischaemic cardiomyopathy, 8 patients received a heart transplantation and 11 patients a VAD, $21 \%$ of patients had previous heart failure surgery (VAD or transplantation). Eight patients had stage 3 or 4 fibrosis ( $42 \%, 2$ patients had cirrhosis and 6 bridging fibrosis, group $\mathrm{F}+$ ), 11 had $0-2$ stage (group $\mathrm{F}-$ ). $\mathrm{F}+$ patients had higher pre-operative right atrial pressure $(16 \pm 9$ vs $11 \pm 4 \mathrm{~mm} \mathrm{Hg}, \mathrm{p}=0.18)$ and a higher incidence of moderate to severe tricuspid regurgitation ( $75 \%$ vs $25 \%, p=0.07$ ), but cardiac index was similar (median 1.7 (IOR 1.4-2.15) in F+ vs 1.8 $(1.4-2.8)$ in $\mathrm{F}-\mathrm{p}=0.60)$. There were no differences in biochemical measurements of renal or liver function: creatinine $97 \mu \mathrm{mol} / 1$ (88-226) in group $\mathrm{F}+$ vs $104(81-113)$ in $\mathrm{F}$-, bilirubin in $\mathrm{F}+30$ $(22-43) \mu \mathrm{mol} / 1$ vs $22(12-53)$ in $\mathrm{F}$-, alanine transaminase $27 \mu \mathrm{mol} / 1(16-231)$ vs $33(18-107)$; and alkaline phosphatase $78 \mu \mathrm{mol} / \mathrm{l}(69-101)$ vs 90 (70-144). A higher international normalised ratio (INR) was seen in $\mathrm{F}+(2.4 \pm 0.6$ vs $1.6 \pm 0.5$, $\mathrm{p}=0.013)$, but $\mathrm{F}+$ had a greater warfarin exposure than $\mathrm{F}-(62 \%$ vs $9 \%, p=0.067)$. To correct for the higher incidence of warfarin therapy in F+ we analysed the Model for End Stage Liver Disease-IX (MELD-IX) score. This was higher in group F+ (19.4 $(14.4-25.6)$ vs $15.2(9.4-21.6), p=0.13)$. Patients in $\mathrm{F}+$ had a higher post-surgery need of blood products than $\mathrm{F}-$ : red blood cell units $38(15-42)$ vs 17 (2-35), $\mathrm{p}=0.18$; plasma units 11 $(6-27)$ vs 7 (1-20), $p=0.43$; and platelets units 9 (5-13) vs 2 $(1-15), p=0.71 . \mathrm{F}+$ patients had a higher bilirubin than $\mathrm{F}-$ at day 8 post-surgery $(127 \mu \mathrm{mol} / 1(48-218)$ vs 20 (17-56), $\mathrm{p}=0.032$ ).

Conclusion Liver fibrosis was common in patients who did not survive heart failure surgery, but could not be predicted from preoperative clinical and biochemical markers, although there was a trend to be associated with more severe tricuspid regurgitation. Fibrosis was associated with more postoperative liver dysfunction.

*FN and TL authors contributed equally to the work. 